\title{
Оптимизация условий получения и свойства керамик бинарной системы $\mathrm{BaNb}_{2} \mathrm{O}_{6}-\mathrm{SrNb}_{2} \mathrm{O}_{6}$ Абубакаров Абу Геланиевич \\ Сайдулаев Хусейн Бекболтович, Зейлингер Станислав Алексеевич Южный федеральный университет \\ Резниченко Лариса Андреевна, д.ф.-м.н. abubakarov12@mail.ru
}

Ниобаты бария $\left(\mathrm{BaNb}_{2} \mathrm{O}_{6}\right)$ и стронция $\left(\mathrm{SrNb}_{2} \mathrm{O}_{6}\right)$, характеризующиеся неординарными электрооптическими, диэлектрическими, пьезо- и пироэлектрическими свойствами [1], являются перспективными материалами для использования в пироэлектрических детекторах, фазовращателях, электрооптических модуляторах, лазерной технике и пр. [2]. Однако сложная структура вольфрамовых бронз, к которым относятся вышеуказанные среды, полиморфизм $\mathrm{BaNb}_{2} \mathrm{O}_{6}$, неизоморфность ему второго крайнего компонента системы - $\mathrm{SrNb}_{2} \mathrm{O}_{6}$ ограничивают ряд твердых растворов (TP) на их основе [3]. Это, а также многоступенчатость процессов образования ТР системы $\left(\mathrm{Ba}_{1-\mathrm{x}} \mathrm{Sr}_{\mathrm{x}}\right) \mathrm{Nb}_{2} \mathrm{O}_{6}$, делают проблематичным изготовление их без примесей посторонних фаз, что существенно затрудняет применение ТР данной системы в качестве функциональных материалов в виде монокристаллов, керамики и тонких пленок. В связи с вышесказанным представляется актуальным оптимизация условий приготовления и установление закономерностей формирования структуры и диэлектрических свойств в $\mathrm{BaNb}_{2} \mathrm{O}_{6}, \mathrm{SrNb}_{2} \mathrm{O}_{6}$ и ТР на их основе, что и стало целью данной работы.

Объектами исследования явились соединения $\mathrm{BaNb}_{2} \mathrm{O}_{6}$ и $\mathrm{SrNb}_{2} \mathrm{O}_{6}$, а также ТР состава $\left(\mathrm{Ba}_{1-\mathrm{x}} \mathrm{Sr}_{\mathrm{x}}\right) \mathrm{Nb}_{2} \mathrm{O}_{6}$, $(0,0 \leq \mathrm{x} \leq 1,0)$, в том числе $\mathrm{Ba}_{0,5} \mathrm{Sr}_{0,5} \mathrm{Nb}_{2} \mathrm{O}_{6}$, используемый нами для получения тонких сегнетоэлектрических пленок Все объекты получены двукратным твердофазным синтезом. Температуры и времена синтеза подбирали в интервалах $T_{\text {синт.1 }}=(1200 \div 1350){ }^{\circ} \mathrm{C}, \tau_{\text {синт.1 }}=(6 \div 10)$ час., $T_{\text {синт.2 }}=(1350 \div 1375){ }^{\circ} \mathrm{C}, \tau_{\text {синт.2 }}=2$ час. Спекание керамик проводили при $T_{\text {сп. }}=(1350 \div 1400){ }^{\circ} \mathrm{C}$ (в зависимости от состава), $\tau_{\text {сп }}=2$ час. Определение

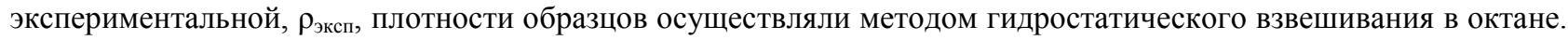
Рентгенографические исследования проводили на дифрактометрах ДРОН 2 и ДРОН 3 (отфильтрованное $\mathrm{Co}_{K \alpha}$-излучение, схема фокусировки по Брэггу-Брентано). Рентгенограммы записывали методом $\theta-2 \theta$ в режиме пошагового сканирования через $0.02 \theta$ по $2 \theta$, время набора импульсов в каждой точке 2 сек. Температурные зависимости действительной части комплексной диэлектрической проницаемости, $\varepsilon^{\prime} / \varepsilon_{0},\left(\varepsilon_{0}-\right.$ электрическая постоянная) и тангенса угла диэлектрических потерь, $\operatorname{tg} \delta$, при $T=(30 \div 300){ }^{\circ} \mathrm{C}$ в диапазоне частот $f=\left(25 \div 10^{6}\right)$ Гц изучали с помощью измерительного стенда на базе LCR METER E7-20. Петли диэлектрического гистерезиса (ДГ) при комнатной температуре на частоте 50 Гц получали на осциллографической установке Сойера - Тауэра. Это позволяло оценить остаточную поляризацию, $P_{\mathrm{R}}$, и коэрцитивное поле, $E_{\mathrm{C}}$, исследуемых образцов.

C ростом температуры обжига содержание примеси в $\mathrm{BaNb}_{2} \mathrm{O}_{6}$ существенно снижается, а при дальнейшем увеличении $T_{\text {синт.1 }}$ остаётся практически неизменным. При $T_{\text {синт.1 }}<1250^{\circ} \mathrm{C}$ и $>1350^{\circ} \mathrm{C}$ двойной ниобат бария кристаллизуется, главным образом, в виде гексагональной фазы, а при $T=1300{ }^{\circ} \mathrm{C}-$ основной фазой является ромбическая. При синтезе двойного ниобата стронция максимальной беспримерности продуктов удаётся достичь при $T \sim 1250{ }^{\circ} \mathrm{C}$, а в $\left(\mathrm{Sr}_{0.5} \mathrm{Ba}_{0.5}\right) \mathrm{Nb}_{2} \mathrm{O}_{6}-$ при $T \sim 1250{ }^{\circ} \mathrm{C}$, при этом увеличение кратности обжигов не приводит к заметному снижению количества примесной фазы. Полученный ТР состава $\mathrm{Ba}_{0,5} \mathrm{Sr}_{0,5} \mathrm{Nb}_{2} \mathrm{O}_{6}$ образуется в тетрагональной сингонии и имеет параметры элементарной ячейки $a=12.355 \AA$, $c=3.896 \AA$ А. Выбор оптимальных температур спекания $\left(T_{\text {сп. }}\right)$ на серии проб, обжигаемых при $(1300 \div 1400){ }^{\circ} \mathrm{C}$, показал, что практически беспримесными с наиболее высокой плотностью являются керамики, полученные при $T_{\text {cп. }}=(1375 \div 1400){ }^{\circ} \mathrm{C}$.

Остаточная поляризация и коэрцитивное поле в $\mathrm{TP} \mathrm{Ba}_{0,5} \mathrm{Sr}_{0,5} \mathrm{Nb}_{2} \mathrm{O}_{6}$ при $E=1.5 \cdot 10^{6} \mathrm{~B} / \mathrm{M}$ составляют, соответственно, $\sim 0.024 \mathrm{Kл} / \mathrm{M}^{2}$ и $\sim 7.2 \cdot 10^{5} \mathrm{~B} / \mathrm{M}$. При комнатной температуре на частоте $f=10^{4}$ Гц $\varepsilon^{\prime} / \varepsilon_{0} \sim 900$ и $\operatorname{tg} \delta$ $\sim 0.05$. С ростом температуры наблюдается формирование максимумов на кривых $\varepsilon^{\prime} / \varepsilon_{0}(T)$ и $\operatorname{tg} \delta(T)$ при $T=90-$ $110{ }^{\circ} \mathrm{C}$, соответствующих области перехода из сегнетоэлектрической (СЭ) в параэлектрическую (ПЭ) фазу и смещающихся при увеличении $f$ в область более высоких температур. Выше температуры Кюри, $T_{\mathrm{C}}$, при $T>$ $125^{\circ} \mathrm{C}$ на зависимостях $\varepsilon^{\prime} / \varepsilon_{0}(T)$ наблюдается частотное расслоение и усиление по мере увеличения $\mathrm{T}$ дисперсии, а на кривых $\operatorname{tg} \delta(T)$ - резкое увеличение значений $\operatorname{tg} \delta$. Наблюдаемое поведение $\varepsilon^{\prime} / \varepsilon_{0}(T, f)$ и $\operatorname{tg} \delta(T, f)$ в окрестности СЭ $\rightarrow$ ПЭ фазового перехода позволяет отнести исследуемый объект к сегнетоэлектрикам с размытым фазовым переходом, что согласуется с [4]. Это связано с флуктуациями химического состава материала из-за неупорядоченного расположения атомов Ba и $\mathrm{Sr}$ в структуре, вследствие которых параметры, определяющие свойства материала, меняются от одного микроучастка к другому, что и приводит к расширению области ФП. Наблюдаемое же поведение $\varepsilon^{\prime} / \varepsilon_{0}(T, f)$ и $\operatorname{tg} \delta(T, f)$ при $T>T_{\mathrm{C}}$ вызвано, скорее всего, ростом электропроводности керамики BSN при высоких температурах. 
Изучены твердые растворы системы $\left(\mathrm{Ba}_{1-\mathrm{x}} \mathrm{Sr}_{\mathrm{x}}\right) \mathrm{Nb}_{2} \mathrm{O}_{6}(0.0 \leq \mathrm{x} \leq 1.0, \Delta \mathrm{x}=0.1)$, проведены исследования структуры, диэлектрических и диссипативных характеристик полученных керамик. По рентгенографическим данным построена фазовая диаграмма и установлена связь макросвойств твердых растворов с фазовой картиной системы. Выявлены твердые растворы с высокими значениями диссипативных характеристик, что позволяет применять их в качестве основы материалов СВЧ - устройств.

Работа выполнена при финансовой поддержке государственного задания (заявки №№ 3.6371.2017/БЧ, 3.6439.2017/БЧ, по ЮФУ №№ БЧ0110-11/2017-35, БЧ0110-11/2017-36) и с использованием оборудования Центра коллективного пользования «Электромагнитные, электромеханические и тепловые свойства твердых тел» НИИ физики Южного федерального университета.

Список публикаций:

[1]. Лайнс М., Гласс А. Сегнетоэлектрические и родственные им материаль, М.: Мир, 736 с, (1981).

[2]. Koo J., Hyeok J.J., Bae B.-S. // J. Am. Ceram., v. 84, № 1, p. 193 - 199, (2001).

[3]. Lee W. - J., Fang T. - T. // J. Am. Ceram., v. 81, № 1, p. $193-199$, (1998).

[4] Кузьминов Ю.С. Сегнетоэлектрические кристаллы для управления лазерным излучением. М. Наука. Главная редакция физико-математической литературы. 1982 г. - 400 c.

\section{Формирование кубического оксикарбида молибдена в низкотемпературной азотной плазме}

\section{Авдеева Юлия Александровна}

Лужкова Ирина Викторовна., Ермаков Алексей Николаевич, Добринский Эдуард Константинович Институт химии твердого тела УрО РАН

Научно-исследовательский институт химии и технологии элементоорганических соединений

Зайнулин Юрий Галиулович, д.х.н. y-avdeeva@list.ru

Кубический оксикарбид молибдена впервые был описан в [1]. Позднее, в ряде литературных данных указывается, что тонкие пленки оксикарбида молибдена могут быть сформированы в процессе различных каталитических реакций [2,3], а соединения на основе Мо2С могут выступать в качестве катализатора при углекислотной конверсии метана [4]. В настоящем исследовании определены закономерности и условия формирования оксикарбида молибдена в ходе плазмохимического синтеза по схеме плазменной переконденсации в низкотемпературной азотной плазме, описанной в работе [5]. Технологические параметры идентичны ранее проведенным исследованиям по переконденсации никелида титана [6] или механических смесей TiC-Ni [7], $\mathrm{VC}-\mathrm{Ni}, \mathrm{VN}-\mathrm{Ni}[8]$.

По данным рентгенографии переконденсированные фракции из бункера и классификаторов 1,2 (циклон, фильтр) имели в своем составе кубические (типа $\mathrm{CsCl}$ ) нитриды молибдена Мo2N с несколько увеличенными параметрами элементарной ячейки, моноклинные молибдаты никеля NiMoO4 и кубический никель. Состав полученных фракций представлен в таблице:

\begin{tabular}{|c|c|c|c|}
\hline $\begin{array}{l}\text { No } \\
n / n\end{array}$ & $\begin{array}{l}\text { Стадии } \\
\text { выгрузки }\end{array}$ & Фазовый состав по данным РФА, (масс.\%) & $\begin{array}{l}\text { Параметры } \\
\text { элементарной } \\
\text { ячейки } \\
\text { тугоплавкой } \\
\text { основы, а (нм) }\end{array}$ \\
\hline \multicolumn{4}{|c|}{ Переконденсированное состояние } \\
\hline 1 & Бункер & $\begin{array}{l}\gamma-\mathrm{Mo}_{2} \mathrm{~N} \text { (np.гp. Pm-3m) - 42, } \mathrm{MoO}_{3} \text { (np.zp. Pbnm) - } \\
28, \mathrm{Ni}(\text { np.zp.Fm-3m) - } 30\end{array}$ & $0,41637\left(\gamma-\mathrm{Mo}_{2} \mathrm{~N}\right)$ \\
\hline 2 & Циклон & 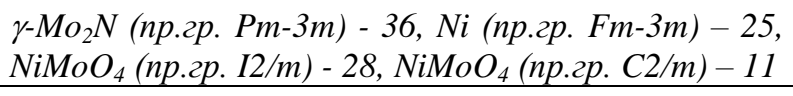 & $0,41694\left(\gamma-\mathrm{Mo}_{2} \mathrm{~N}\right)$ \\
\hline 3 & Фильтр & $\begin{array}{l}\gamma-\mathrm{Mo}_{2} \mathrm{~N}\left(\text { (np.гp. Pm-3m) - 35, } \mathrm{NiMoO}_{4}(\text { np.гp. C2/m) - }\right. \\
\text { 36, } \mathrm{NiMoO}_{4}(\text { np. гp. I2/m) - } 29\end{array}$ & $0,416780\left(\gamma-\mathrm{Mo}_{2} \mathrm{~N}\right)$ \\
\hline
\end{tabular}

Никельсодержащие компоненты, указанные в таблице впоследствии были удалены при 30-минутном кипячении нанокомпозиций в разбавленной $(1: 1) \mathrm{HCl}$. Рентгенофазовый анализ протравленных композиций 